\title{
MODIFIKASI ALAT BANTU GERINDA SILINDRIS UNTUK MENINGKATKAN FUNGSI MESIN BUBUT
}

\author{
Hendra Saputra Pratama ${ }^{1}$, Ronny Tuhumena ${ }^{2}$ \\ ${ }^{1,2}$ Jurusan Teknik Mesin, Fakultas Teknik Universitas Negeri Surabaya \\ hendrapratama@unesa.ac.id
}

\begin{abstract}
Abstrak - Pemesinan adalah salah suatu bagian dari industri manufaktur. Pemesinan memegang peranan penting di dalam produksi mesin dan komponen mesin. Proses pemesinan meliputi mesin perkakas yaitu mesin bubut, mesin frais, mesin sekrap, mesin bor, mesin gerinda duduk, mesin gerinda silindris, mesin gerinda datar, mesin pons, dan lain-lain. Untuk meningkatkan fungsi mesin bubut menjadi gerinda silindris dapat di lakukan dengan menambahkan alat bantu gerinda silindris yang dipasang pada dudukan tool post. Komponen alat bantu ini meliputi motor listrik, bantalan (bearing), poros, pulley, dan $V$-belt. Fungsi komponen alat bantu ini adalah motor listrik sebagai elemen penggerak, bantalan (bearing) untuk memutarkan poros yang dihubungkan dengan batu gerinda, poros dan sebagai elemen transmisi yang digerakan digunakan pulley dan $V$-belt. Dengan alat bantu gerinda silindris yang di pasang pada mesin bubut ini bisa menghasilkan produk kesilindrisan yang sama dengan produk mesin gerinda silindris.
\end{abstract}

Kata Kunci-Mesin bubut, Alat bantu gerinda silindris, Tool post, Kesilindrisan.

\begin{abstract}
Machining is one part of the manufacturing industry. Machining plays an important role in the production of machinery and machinery components. Machining process includes tool machine, lathes, frais machine, fuse machine, drill machine, sitting grinding machine, cylindrical grinding machine, flat grinding machine, punch machine, etc. To improve the function of lathe becomes cylindrical grinders can be done by adding a cylindrical grinding tool installed on the Post tool holder. Components of these aids include electric motors, bearings, shafts, pulleys, and belts. The component functions of this tool are electric motors as the drive elements, bearings for rotating the shafts associated with grinding stones, shafts and as transmission elements in motion are used pulley and belt. With the cylindrical grinding aids that are installed on the lathe, it can produce the same product with cylindrical grinding machine products.
\end{abstract}

Kata Kunci- Lathes, Cylindrical grinders, Tool post, Cylindrical.

\section{PENDAHULUAN}

Saat ini industri memegang peranan penting dalam kehidupan. Perkembangan ilmu pengetahuan dan teknologi, berdampak pada kemajuan industri manufaktur. Banyak perusahaan berusaha untuk menekan biaya produksi dan mempercepat proses produksi tanpa mengurangi kualitas dari produk yang dihasilkan, sehingga dapat meningkatkan keuntungan yang diperoleh perusahaan. Cara untuk mempercepat proses produksi antara lain dengan meminimalkan waktu setting benda kerja pada saat proses permesinan.

Jurusan Teknik Fakultas Teknik Mesin Universitas Negeri Surabaya (Unesa) sebagai lembaga pendidikan tinggi yang bergerak di bidang Pendidikan Teknologi Kejuruan, terus berupaya meningkatkan efektivitas dan efisiensi keberhasilan pendidikan, baik keberhasilan internal maupun keberhasilan eksternal dari pendidikan yang dilaksanakan. Keberhasilan internal sistem pendidikan dapat terakumulasi dalam kuantitas dan kualitas hasil pendidikan, yakni kemampuan lulusan.

Jurusan Teknik Fakultas Teknik Mesin Universitas Negeri Surabaya (Unesa) memiliki laboratorium pemesinan dimana ada praktek mesin bubut, praktek mesin frais, praktek mesin sekrap, praktek mesin bor, praktek mesin gerinda duduk, praktek mesin gerinda silindris, praktek mesin gerinda datar, praktek mesin pons, dan lain-lain yang semuanya ada dalam mata kuliah pemesinan. Namun mesin gerinda silindris belum dimiliki oleh laboratorium ini. Seharusnya dalam dunia pendidikan yang berhubungan dengan praktek teknik manufaktur untuk mendukung proses pembelajaran dalam upaya mencapai standard kompetensi bidang pemesinan, hal tersebut sangat di butuhkan. Hanya saja harga mesin grinding silindris cukup mahal, maka untuk menghemat biaya dapat dilakukan modifikasi mesin bubut konvesional dengan cara menambahkan alat bantu gerinda silindris yang di pasang pada dudukan tool post mesin bubut. Alat bantu ini memiliki fungsi yang sama dengan mesin grinding silindris yang mudah dibongkar maupun dipasang kembali sehingga proses grinding silindris dapat menggantikan praktek gerinda silindris yang belum ada pada laboratorium pemesinan.

Berdasarkan latar belakang diatas, dapat dirumuskan masalah bagaimana merancang dan membuat alat bantu gerinda silindris yang dapat dipasang pada mesin bubut yang dapat meningkatkan fungsi mesin gerinda.

Perancangan dan pembuatan alat bantu gerinda silindris yang dipasangkan pada mesin bubut ini, di batasi pada pembuatan alat bantu gerinda silindris hanya untuk proses penggerindaan lurus bagian luar bentuk silindris dan tidak bisa membuat benda kerja silindris bagian dalam maupun bentuk tirus. 
Tujuan yang ingin dicapai dalam penelitian ini adalah:

1. Untuk Meningkatkan Fungsi Mesin Bubut.

2. Meyelesaikan masalah yang ada pada laboratorium pemesinan, khususnya masalah pengadaan mesin gerinda silindris yang membutuhkan dana yang tidak sedikit.

\section{Mesin Bubut Konvensional}

Mesin bubut konvensional merupakan mesin bubut yang dalam penggunaanya sebagian besar dilakukan secara manual oleh operator. Untuk itu memerlukan keterampilan dan feeling yang baik dari operator untuk menghasilkan benda-benda yang berkualitas. Terkadang mesin ini juga memiliki mekanisme penggerak otomatis (semi otomatis)

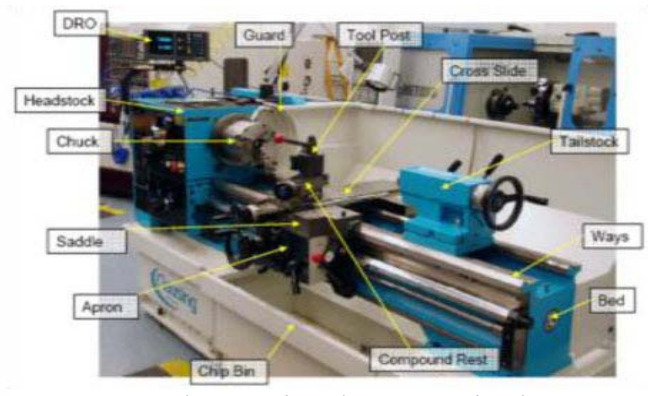

Gbr 1. Mesin Bubut Konvensional

\section{Elemen Dasar Proses Bubut}

Elemen dasar dari proses bubut dapat diketahui atau dihitung dengan menggunakan rumus yang dapat diturunkan, elemen dasar dapat dihitung dengan rumus - rumus dibawah ini :

Kecepatan Potong (V), adalah jumlah putaran spindle atau cutter. Persatuan waktu (menit) untuk mencari kecepatan potong dengan menggunakan rumus dibawah ini :

dimana,

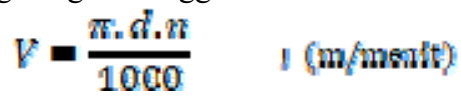

$\mathrm{d}=$ diameter rata-rata $(\mathrm{mm})$

$\mathrm{n}=$ putaran Poros Utama (r/menit)

$$
d=\frac{d Q+d m}{2} \quad,(m / m a n l)
$$

\section{Mesin Gerinda Silindris}

Ada beragam macam tipe mesin gerinda silindris, yaitu:

a. External cylindrical grinding machine

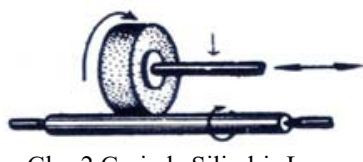

b. Internal cylindrical grinding machine

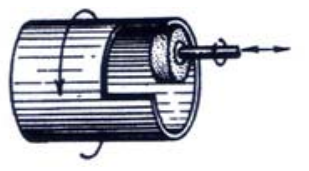

Gbr. 3 Gerinda Silindris Dalam

\section{c. Universal cylindrical grinding machine}

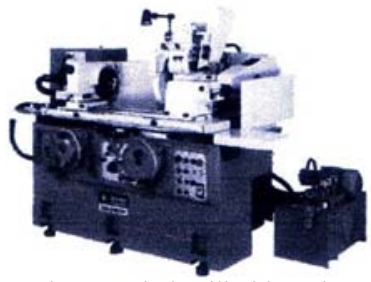

Gbr. 4 Gerinda Silindris Universal

\section{d. Centreless cylindrical grinding machine}
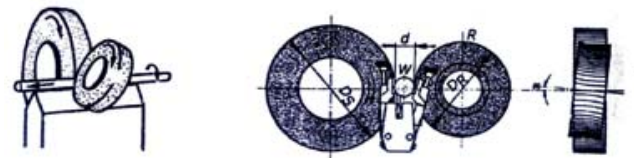

Gbr. 5 Gerinda Silindris Terpusat

\section{Elemen Dasar Proses Gerinda}

Elemen Dasar Proses Gerinda, proses gerinda dilaksanakan dengan mesin gerinda dengan pahat yang berupa batu gerinda berbentuk piringan (grinding wheel/disk) yang dibuat dari campuran serbuk abrasif dan bahan pengikat dengan komposisi dan struktur tertentu. Batu gerinda yang dipasang pada spindel/poros utama tersebut berputar dengan kecepatan tertentu. Tergantung pada diameter batu gerinda dan putarannya, maka kecepatan periferal pada tepi batu gerinda dapat dihitung dengan rumus berikut:

$$
V s=\frac{\pi{ }^{2} d s, \pi s}{1000} \quad \text { I (m/msit) }
$$

dimana,

$\mathrm{Vs}=$ kecepatan periferal batu gerinda (peripheral wheel speed), biasanya berharga sekitar $20-60 \mathrm{~m} /$ menit

$\mathrm{ds}=$ diameter batu gerinda $(\mathrm{mm})$

$\mathrm{ns}=$ putaran batu gerinda $(\mathrm{r} / \mathrm{menit})$

Tergantung pada bentuk permukaan yang dihasilkan, pada garis besarnya proses gerinda dapat diklasifikasikan menjadi 2 jenis dasar yaitu;

- Proses gerinda Silindris (Cylindrical Grinding) untuk menghasilkan permukaan silindris, dan

- Proses gerinda rata (Surface Grinding), bagi penggerindaan permukaan datar.

Proses gerinda silindris yang dilakukan dengan mesin gerinda silindris (Cylindrical Grinding Machine) memerlukan putaran benda kerja. Oleh sebab itu dapat didefinisikan kecepatan periferal benda kerja yaitu:

$$
w=\frac{\pi w^{w} w W^{2}}{60.000} \quad,(\mathrm{~m} / \mathrm{mon} / \mathrm{t})
$$




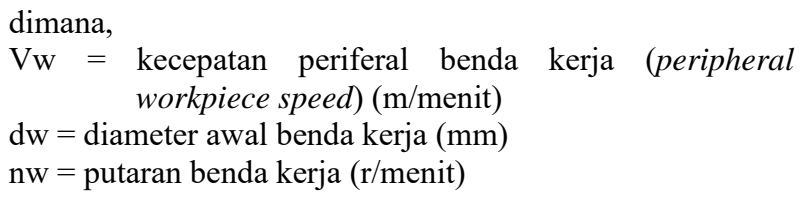

Kecepatan periferal benda kerja ini jauh lebih kecil dari pada kecepatan periferal batu gerinda. Rasio kecepatannya berharga sekitar:

$$
q=\frac{V s}{b w} \text { Raslo ksopatan }=20 f_{1} \mathrm{~d}, 120 \quad \mathrm{f}: \text { ) }
$$

Pada mesin gerinda silindris putaran batu gerinda biasanya hanya ada satu harga saja.

\section{METODE}

Penelitian ini dilakukan di jurusan Teknik Mesin Universitas Negeri Surabaya dengan rentang waktu pelaksanaan bulan April hingga bulan Desember 2019. Adapun diagram alir penelitian pada perancangan alat bantu gerinda silindris ini adalah sebagai berikut;

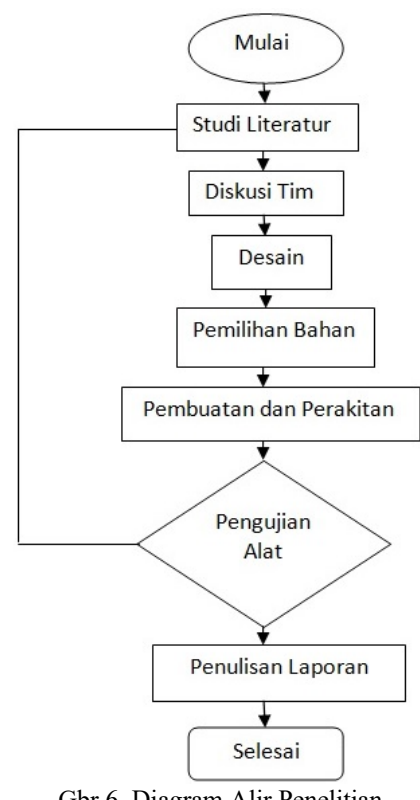

Gbr 6. Diagram Alir Penelitian

\section{HASIL DAN DISKUSI}

Pada pembuatan konsep mesin dibuat sebanyak mungkin alternatif konsep mesin yang semuanya memenuhi semua butir dari tuntutan mesin. Konsep mesin masih berupa gambar skema yang terdiri dari elemen-elemen mesin. Elemen mesin yang berupa rangka tersebut harus diberi bentuk dalam fase perancangan berikutnya yaitu fase pembuatan rancangan mesin. Pada tahapan ini dilakukan pemecahan masalah dengan menggunakan black box untuk menentukan fungsi bagian utama. Mesin ini dirancang karena adanya kebutuhan dan tuntutan terhadap proses akhir dari produk seperti poros harus dilakukan penggerindaan silindris. Beberapa kendala yang dapat menghambat suatu perusahaan memproduksi produk yaitu ketersediaan mesin yang tidak ada pada saat proses akhir produk.

Analisa black box digunakan sebagai indikator dari masukan proses dan luaran pada gambar ini berikut adalah analisa black box yang digunakan.

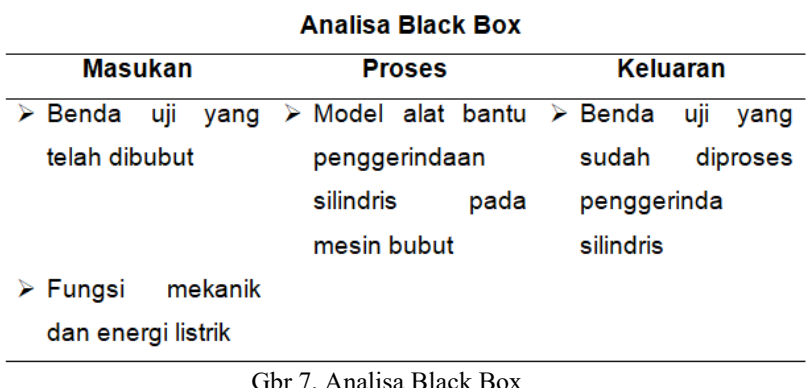

Perhitungan Rancangan

Material benda kerja baja karbon rendah dimana diketahui :

Kecepatan batu gerinda $(\mathrm{N}) \quad: 4459 \mathrm{rpm}$

Diameter batu gerinda $\quad: 130 \mathrm{~mm}=5,2$ in

Lebar batu gerinda (w) $\quad: 18 \mathrm{~mm}=0,70$ in

Lubang (hole)

$: 13$

Kedalaman patung (f)

Feeding (v)

: $0,03 \mathrm{~mm}-0,00118 \mathrm{~mm}$

$: 10 \mathrm{in} / \mathrm{min}$

Kecepatan pemakanan

$\mathrm{MRR}=\mathrm{f} \times \mathrm{w} \times \mathrm{v}$

$=0,00118$ in $\times 0,70$ in $\times 10 \mathrm{in} / \mathrm{min}=0,00826$

\begin{tabular}{|l|c|c|c|}
\hline \multirow{2}{*}{ Material } & \multirow{2}{*}{ Hardness } & \multicolumn{2}{c|}{ Spesifik Energi } \\
\cline { 3 - 4 } & & $\mathbf{w . x} / \mathbf{m m}^{\mathbf{3}}$ & Hp.min/in \\
\hline Almunium & $150 \mathrm{HB}$ & $7-27$ & $2,5-10$ \\
Cost iron & $215 \mathrm{HB}$ & $12-60$ & $4,5-22$ \\
Low carbon steel & $110 \mathrm{HB}$ & $14-68$ & $5-25$ \\
Titanium alloy & $300 \mathrm{HB}$ & $16-55$ & $6-20$ \\
Tool steel & $37 \mathrm{HRC}$ & $18-82$ & $6,5-30$ \\
\hline
\end{tabular}

$$
\text { Daya motor } \begin{aligned}
\mathrm{P} & =\mathrm{N} \times \mathrm{MRR} \\
& =25 \mathrm{hp} \mathrm{min} / \mathrm{in}^{3} \times 0,00826 \\
& =0,206 \mathrm{hp}
\end{aligned}
$$

Motor yang digunakan adalah motor $0,5 \mathrm{hp}$ dengan kecepatan $1400 \mathrm{rpm}$.

Konsep desain yang akan dibuat adalah seperti pada gambar berikut ini: 


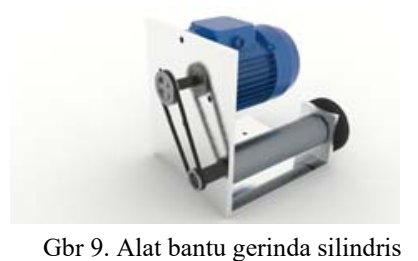

\section{Perhitungan Transmisi Sabuk}

Dalam perancangan, digunakan electromotor dengan $\mathrm{n}_{\text {motor }}$ $=1400 \mathrm{rpm}$

Transmisi menggunakan sabuk V standard

Diketahui:

Diameter maksimal pulley tergerak $\mathrm{d}_{\mathrm{m} 2}=51 \mathrm{~mm}$

Diameter pulley penggerak

$$
\mathrm{d}_{\mathrm{m} 1}=\frac{n_{2} \times d_{m 2}}{n_{1}}=\frac{4459}{1400}=162,4
$$

Berdasarkan standar pulley yang ada di pasaran maka dipilih pulley dengan diameter 152,4 atau 6 in.

Kecepatan keliling batu gerinda

$$
\begin{aligned}
& \mathrm{V}=\frac{n_{\text {tergerak }} \times d_{\text {batu gerinda }} \times \pi}{1000}=\frac{4459 \times 130 \times \pi}{1000}= \\
& 1820,16 \mathrm{~mm} / \mathrm{min}
\end{aligned}
$$

Kec. Pulley penggerak $v_{1}$

$$
\begin{aligned}
& v_{1}=\frac{\pi \times d m_{1} \times n_{\text {motor }}}{60 \times 1000}=\frac{\pi \times 162,4 \times 1400}{6000} \\
& =11,8 \mathrm{~m} / \mathrm{s}
\end{aligned}
$$

Panjang sabuk $\mathrm{L}_{\mathrm{mr}}=2 \mathrm{~L}_{\mathrm{a}}+1,57\left(\mathrm{~d}_{\mathrm{m} 2}+\mathrm{d}_{\mathrm{m} 1}\right)+\frac{\left(d_{m 1}-d_{m 2}\right)^{2}}{4 L_{a}}$

$$
=2 \times 150+1,57(51+162,4)+\frac{162,4}{4 \times 150}=636,17 \mathrm{~mm}
$$

Dimana, $\mathrm{L}_{\mathrm{a}}=$ jarak poros

Panjang dalam $\mathrm{L}_{\mathrm{a}}=\mathrm{Lmr}-2 \times \mathrm{b}=636,17-2 \times 10$

$\mathrm{L}_{\mathrm{a}} \quad=616 \mathrm{~mm}$

$$
=616,14 \mathrm{~mm}
$$

Panjang sabuk sebenarnya $\mathrm{L}_{\mathrm{m}}=\mathrm{L}_{\mathrm{ir}}+2 \mathrm{x} \mathrm{b}=616+2 \times 10=$

$636 \mathrm{~mm}$

Dimana, $\mathrm{b}=$ lebar sabuk

Berdasarkan tabel convensional V-Belt Mitsuboshi dan ketersediaan $\mathrm{V}$ belt standar di pasar, maka dipilih sabuk $\mathrm{V}$ standar tipe $\mathrm{M}$ dengan lebar sabuk $\mathrm{b}=10 \mathrm{~mm}$ dan panjang sabuk sebesar $635 \mathrm{~mm}$, dengan kata lain $\mathrm{V}$ belt yang dipilih adalah M25. Jumlah sabuk $\mathrm{z}=1$ buah.

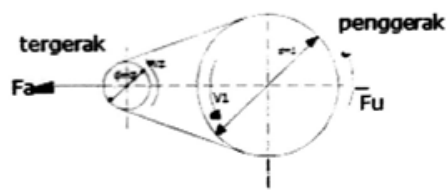

Gbr 10. Gaya keliling dan gaya pada poros
Torsi $\mathrm{T}=\frac{60 \times P}{2 \times \pi \times N}=\frac{6 \times 183,87}{2 \times \pi \times 1400}=1,25 \mathrm{Nm}$

Dimana $1 \mathrm{hp}=735,499 \mathrm{~W}$

Gaya keliling $\mathrm{Fu}=\frac{2 \times T}{d m 1}=\frac{2 \times 1,25}{0,1524}=16 \mathrm{~N}$

Gaya poros $\mathrm{Fa}=2 \times \mathrm{Fu}=2 \times 16=32 \mathrm{~N}$

Material poros penyangga dan poros transmisi untuk pembebanan normal, misal mesin perkakas dengan baja konstruksi umum; St. 37, St. 42, St. 50, St. 70. DIN 17 100, maka dipilih material poros adalah St. 70 dengan data sebagai berikut (Poros Penyangga dan Transmisi, Sudibyo).

Batas patah $\sigma_{\mathrm{b}}=700 \mathrm{~N} / \mathrm{mm}^{2}$

Batas patah/tekuk ganti $\sigma_{\text {bw }}=340 \mathrm{~N} / \mathrm{mm}^{2}$

Batas puntir kontinyu $\tau_{\text {tsch }}=260 \mathrm{~N} / \mathrm{mm}^{2}$

Faktor batas tegangan dinamik $\alpha_{0}=\frac{\sigma_{b w}}{1,73 \cdot \tau_{t s c h}}=$

$$
\frac{340}{1,73 \cdot 260}=0,756
$$

Momen gabungan $\mathrm{M}_{1}=\sqrt{M_{A \max }{ }^{2}+0,75\left(\alpha_{0}-T\right)^{2}}$

$\sqrt{5146,87^{2}+0,75 \cdot(0,705 \cdot 1250)^{2}}=5211,5 \mathrm{Nmm}$

Angka keamanan $v=1,5-2,5$ (jika frekuensi pembebanan maksimum mencapai $50 \%$ dan pembebanan normal, misalnya mesin perkakas. (Kekuatan dan Tegangan Ijin, Sudibyo)

Tegangan ijin sementara $\bar{\sigma}_{B s c m}=\frac{\sigma_{b w}}{v}=\frac{340}{2,5}=136 \mathrm{~N} / \mathrm{mm}^{2}$

Diameter sementara $\mathrm{d}=\sqrt{\frac{M_{1}}{0,1 \cdot \bar{\sigma}_{b s e m}}}=\sqrt{\frac{5211,5}{0,1.136}}$

$$
=7,26 \mathrm{~mm}
$$

Jadi diameter minimal poros adalah 7,26 $\mathrm{mm}$. Sesuai dengan konsep desain awal diameter poros minimal $20 \mathrm{~mm}$.

\section{Uji Coba Alat Bantu}

Dalam melakukan sebuah percobaan alat, sering terjadi error. Apabila dalam hasil uji coba alat, mengalami gangguan, sebaiknya dilakukan perbaikan pada gangguan tersebut. Percobaan yang dilakukan harus berulang kali, pada alat bantu yang dirancang untuk mengetahui hasil percobaan sesuai dengan standard.

\begin{tabular}{llllc}
\hline \multicolumn{4}{c}{ Pengukuran benda uji $\not{0}$} & $15 \mathrm{~mm}$ dengan alat ukur mikrometer \\
\hline No & Gambar & $\begin{array}{c}\text { Objek } \\
\text { Kesilindrisan }\end{array}$ & $\begin{array}{c}\text { Standard } \\
0,001 \mathrm{~mm}\end{array}$ & $\begin{array}{c}\text { Hasil } \\
14,97 \mathrm{~mm}\end{array}$ \\
& & & &
\end{tabular}


Pengukuran benda uji $\emptyset 15 \mathrm{~mm}$ dengan alat ukur mikrometer

$2 \quad$ Kesilindrisan $0,001 \mathrm{~mm} \quad 14,97 \mathrm{~mm}$

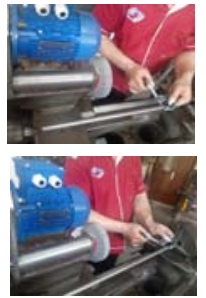

Hasil rata-rata $14,97 \mathrm{~mm}$

\begin{tabular}{|c|c|c|c|c|}
\hline \multicolumn{5}{|c|}{ Pengukuran benda uji $\emptyset 15 \mathrm{~mm}$ dengan dial indicator } \\
\hline No & Gambar & Objek & Standard & Hasil \\
\hline 1 & & Kesumbuan & $0,002 \mathrm{~mm}$ & $0,006 \mathrm{~mm}$ \\
\hline 2 & & Kesumbuan & $0,002 \mathrm{~mm}$ & $0,006 \mathrm{~mm}$ \\
\hline 3 & & Kesumbuan & $0,002 \mathrm{~mm}$ & $0,006 \mathrm{~mm}$ \\
\hline
\end{tabular}

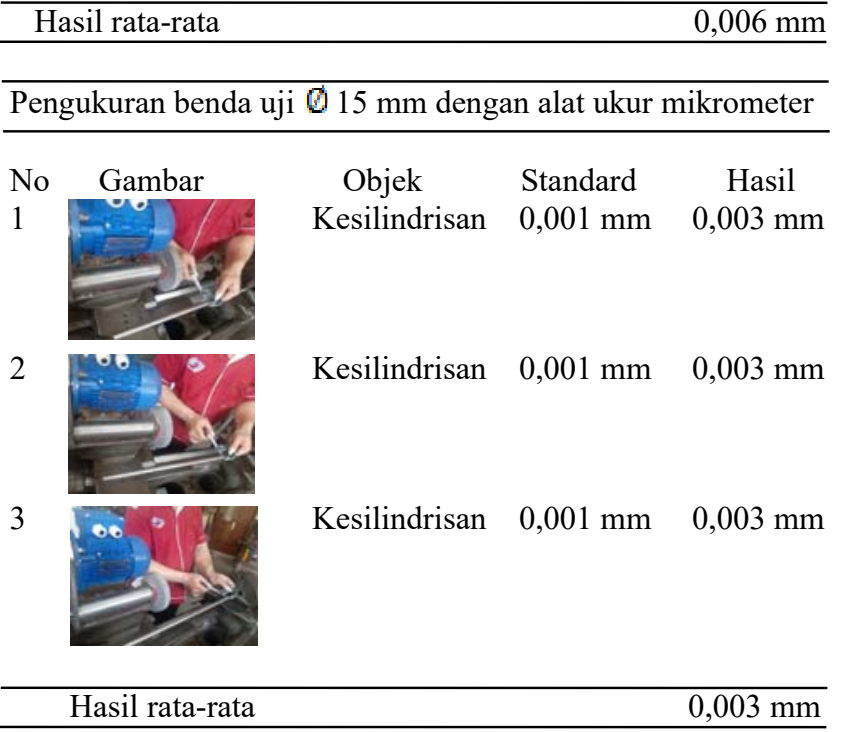

\section{KESIMPULAN}

Berdasarkan hasil pembuatan alat bantu dan uji coba alat bantu gerinda silindris, maka dapat diambil kesimpulan :
1. Uji benda hasil percobaan untuk diameter $15 \mathrm{~mm}$, dengan menggunakan alat ukur micrometer untuk kesilindrisan rata-rata $14,97 \mathrm{~mm}$.

2. Uji benda hasil percobaan untuk diameter $15 \mathrm{~mm}$, dengan menggunakan alat ukur dial indicator untuk kesumbuan rata-rata $0,006 \mathrm{~mm}$.

3. Uji benda hasil percobaan untuk diameter $15 \mathrm{~mm}$, dengan menggunakan alat ukur micrometer untuk kesilindrisan rata-rata $0,003 \mathrm{~mm}$.

\section{UCAPAN TERIMA KASIH}

Terima kasih kepada Universitas Negeri Surabaya atas pemberian bantuan dana Penelitian PNBP, sehingga penulis bisa menyelesaikan dan mendapatkan manfaat dari penelitian ini.

\section{REFERENSI}

[1] Husman, "Alat Bantu Khusus Gerinda Silindris Luar Pada Mesin Bubut" Laporan Akhir Thesis Pasca Sarjana, Institut Teknologi Sepuluh November, Surabaya, 2013.

[2] Mechanical Engineering, Bagian Bagian Mesin Bubut [Online], diakses pada tanggal 14 agustus 2017, Available:http://www.mechanical engineering.net/.

[3] Dedy Prastiawan, "Rancang Bangun Alat Gerinda Silindris Permukaan Luar Pada Mesin Bubut Konvensional" Laporan Akhir Proyek Akhir', Universitas Sebelas Maret, Surakarta, 2010

[4] Sularso dan Kiyakotsu Suga, Dasar Perencanaan dan Pemilihan Elemen Mesin, Jakarta: PT Pradaya Paramita, 2002 [Hal 1-28, 103-104, 163, 296299].

[5] Taufiq Rochim, “Teori \& Teknologi Proses Permesinan”, ITB bandung, Higher Education Development Support Project, 1993. [Hal 23-24]. 